\title{
THE SYSTEMIC DESIGN APPROACH: A LOWER ENVIRONMENTAL IMPACT EVENT
}

\author{
Mingrone Lorena* \\ Politecnico di Torino \\ Viale Mattioli 39, 10125, Torino, Italy \\ Tel. (+39) 0110906540 \\ E-mail: lorena.mingrone@polito.it \\ Montrucchio Valeria \\ Politecnico di Torino \\ Viale Mattioli 39, 10125, Torino, Italy \\ Tel. (+39) 0110906540 \\ E-mail: valeria.montrucchio@polito.it
}

\begin{abstract}
The aim of the research is to provide a method for a systemic project of an event, which involves all stakeholders, in relation with the surrounding community and with environmental issues.

Usually at the end of an event, materials and products become waste without any quantitative or qualitative value.

The application of the systemic approach reverses this trend: attention is focused on the event in its entirety. It becomes possible to highlight three phases: pre-event, event and post-event.

We can thus set in motion relationships that promote the use of input and output flows of material and energy, in order to don't generate waste.

The analyzed parameters permit to assess the environmental repercussion of the event relate to the material, resources, energy, waste, logistics, communication, dimension of the event and social impact.

The qualitative and quantitative analysis of the collected data outlines the holistic relief, which helps to assess the complexity of the event.

Linking input and output information, the designer looks at waste as a resource and creates secondgeneration products.

Therefore the innovation process is mainly a cultural change, which is possible only through a review of the priorities of the event project.

This changing in project priorities allows a systemic analysis of different scenarios: all the events can be designed under the critical eye of ethical choices, in order to reduce the environmental impact.
\end{abstract}

Keywords: systemic, waste, resource, flows, event

\section{Introduction}

Sharing, meeting and funning are the principal goal of events, conferences and exhibitions.

Following the common thinking, the project of an event has two main objectives: the result of the event and the customer satisfaction.

In order to obtain a successful event, is really important the choice of the location and the services, but also the cooperation between each involved subject has a main role.

\footnotetext{
${ }^{*}$ Corresponding author
} 
Therefore, in order to improve the event, the designer is inclined on spectacular solutions; unfortunately these installations have a very short life.

Frequently, the life of an exhibition begins with its project and finishes with its dismounting.

The success of an event is due to many spectacular and attractive elements; after the event, the same elements became waste without any value.

In order to reduce the environmental impact, it's important to think about the quick passage of all the products of an event: from value to waste. For that reason it's important that the designer try to reduce the waste and to reuse as much as possible all the resources.

\section{Event description}

\subsection{Temporal phases of the event}

Follow a changing on the way to change event project, first of all we should analyze, upstream, all the actions, then we should reduce, downstream, the dangerous ones.

Following this methodology it becomes important, not only the creation of the event, but also the whole analysis of the exhibition. In order to reach a total reading of the event, we should think about a long time period. In that way, the growth and the realization of the event, will be anticipated by the "pre-event phase" and follow by the "post-event phase".

Through the "pre-event phase", we could define:

- the management factor (about services, energy, water, catering, waste, cleaning, transportation)

- the productive factor (mounting and promotion)

- the economic factor (partners and sponsors)

Thanks to these kinds of decisions, during the event it will be possible to have a correct management of material and energy flows. The "post-event" phase allows the recovery and the valorisation of the waste, considered as resources.

This changing on the priority of the project permits to analyze the scenarios of each exhibition with a systemic approach.

Applying the Systemic Design methodology, all of these scenarios will be project through ethic environmental chooses.

\subsection{Involved subjects}

Thanks to this approach-change, it's possible to underline all the subjects, which, in different moment, involve and organize the event. The event is focused on the passive (spectator) and active (actor) public. At the same time, each person is part of a community, located in the territory of the event. Thinking about the moment of the show, it is possible to define a "near community" and a "far one". Public and private agencies are also part of the community; these entities promote, finance and, sometimes, realize the event.

\section{Research}

\subsection{Methodology: Systemic Design approach}

We can consider the whole event as a complex system, not always designed according to the environmental rules.

Applying the Systemic Design methodology becomes possible to link every part, creating a sort of a social net, where each subject can share its knowledge and qualities.

The growth of the net establishes not only a flux of information, but also energy and material flows. Each subject is able to put in relation all kind of input and output flows, and to analyse quality and quantity of material and energy: before, during and after the exhibition. (Figure 1) 
After the realization of the links, the subjects become part of a conscious group. It is possible to consider this group as a "nucleus", which project the event in order to follow the environmental sustainability and to reduce the possible dangerous effect.

The systemic approach allows the evolution and the cooperation of all involved subjects.

Above all, this innovation process is a cultural change: it is possible only through a review of the priorities of the event plan.

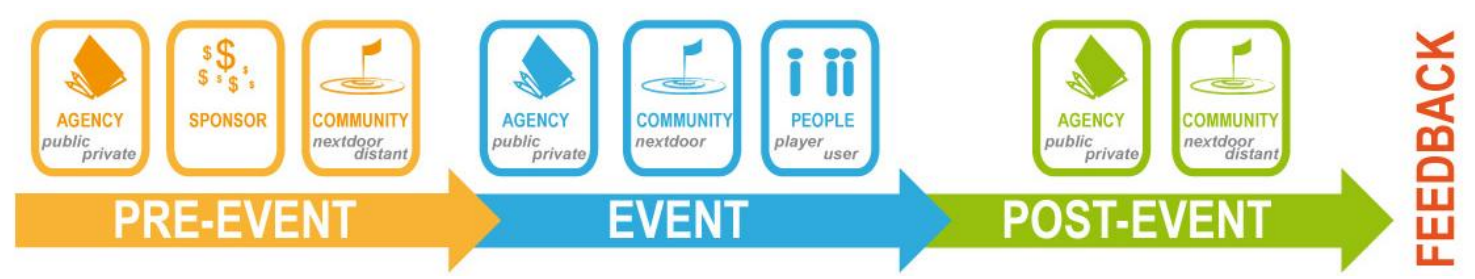

Figure 1. Event phases.

\subsection{Holistic relief}

A plan of an event is a complex work, which involves a lot of subjects and different fields of action.

The Systemic Design approach re-designs the whole "event system", according with its cultural and working line guides. Through the holistic relief and the consequently parametric assessments, the designer will be able to make the right decisions about materials, products, services and territorial operators, for the polity of the event. In order to assess the environmental impact of an event - exhibition, concert, and so on - it's important to collect information about all the involved sectors.

The qualitative and quantitative analysis of the collected data permits an exhaustive holistic relief, useful to value the complexity of the event and its environmental impact.

In order to simplify the analysis of the collected information, it is possible to divide all the data into four main groups: energy, food, logistic and communication.

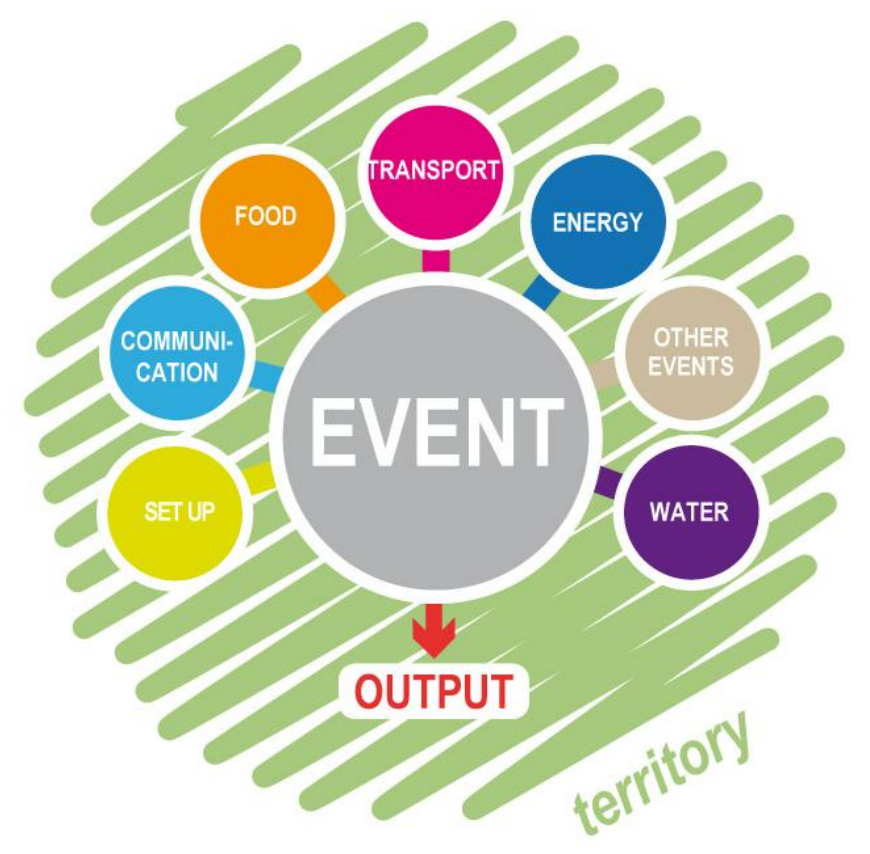

Figure 2. Holistic relief. 


\subsection{Energy}

The "event system" needs energy for its technical plants' working.

Permanent structures use the local electric grid for the energy supply; temporary exhibitions use fuel generator.

The main problems about the "energy field" are strictly linked to the kind of the power source.

In order to reduce and minimize the dangerous effect, a possible solution could be to use a local renewable power source. For example a natural fuel instead of the diesel oil could reduce the dangerous $\mathrm{CO} 2$ emissions around the $95 \%{ }^{1}$

\subsection{Food}

In the matter of the "food", in each event there is a dedicated area - bar, coffee station, restaurant and so on - with different dimension and food quality, depending on the kind of the exhibition.

According to each different event, there are different equipment for the cooking preparation and fruition of the food. Each different food station has different environmental impact: for example tools for food and drink fruition have an important role on the environmental footprint.

The event needs to have a separate collection of rubbish, but this is not enough: in order to minimize the environmental impact, designer should think about environmental impact of each material.

Regarding case study of "Salone del Gusto 2008": using biodegradable material food-set, instead of plastic ones, there were saved around $68 \mathrm{Kg}$ of CO2 for 1,000 food-sets.

\subsection{Logistic}

The "logistic area" includes transportation and movement for both materials and people: frequently the main emissions are caused by the logistic.

Usually there isn't a "zero km" logistic, with a consequent increase of the CO2 emissions.

In the matter of the transportation, it's very important also the logistic of the people: how many people are moving and what kinds of means of transporting they are using.

In order to reduce the environmental impact, the choice of the means of transporting and their capacity, has a massive influence on the total emission amount.

\subsection{Communication}

The event is also built through its promotion.

About the "communication field" materials for merchandising and for advertising are responsible of dangerous emissions.

In order to obtain a sustainable event, it will be appropriate to choose an environmental friendly communication: green material, less use of paper, etc.

According to a sustainability approach, for example, using the "Evergreen material" ${ }^{3}$ instead of plastic one, it is possible to reduce the $\mathrm{CO} 2$ emissions of $35 \%$, more or less.

\footnotetext{
${ }^{1}$ Direttiva (RES) 2009/28/CE, Allegato 3

${ }^{2}$ The "Salone del Gusto" is an important event in Turin, which involves all the people of the world who take care deeply about the food and the environment. http://press.slowfood.it/press/ita/leggi.lasso?cod=C2744B88189661FD2Duwm10F69AF\&ln=it

${ }^{3} \mathrm{http}: / / \mathrm{www}$. ever-green.it/
} 


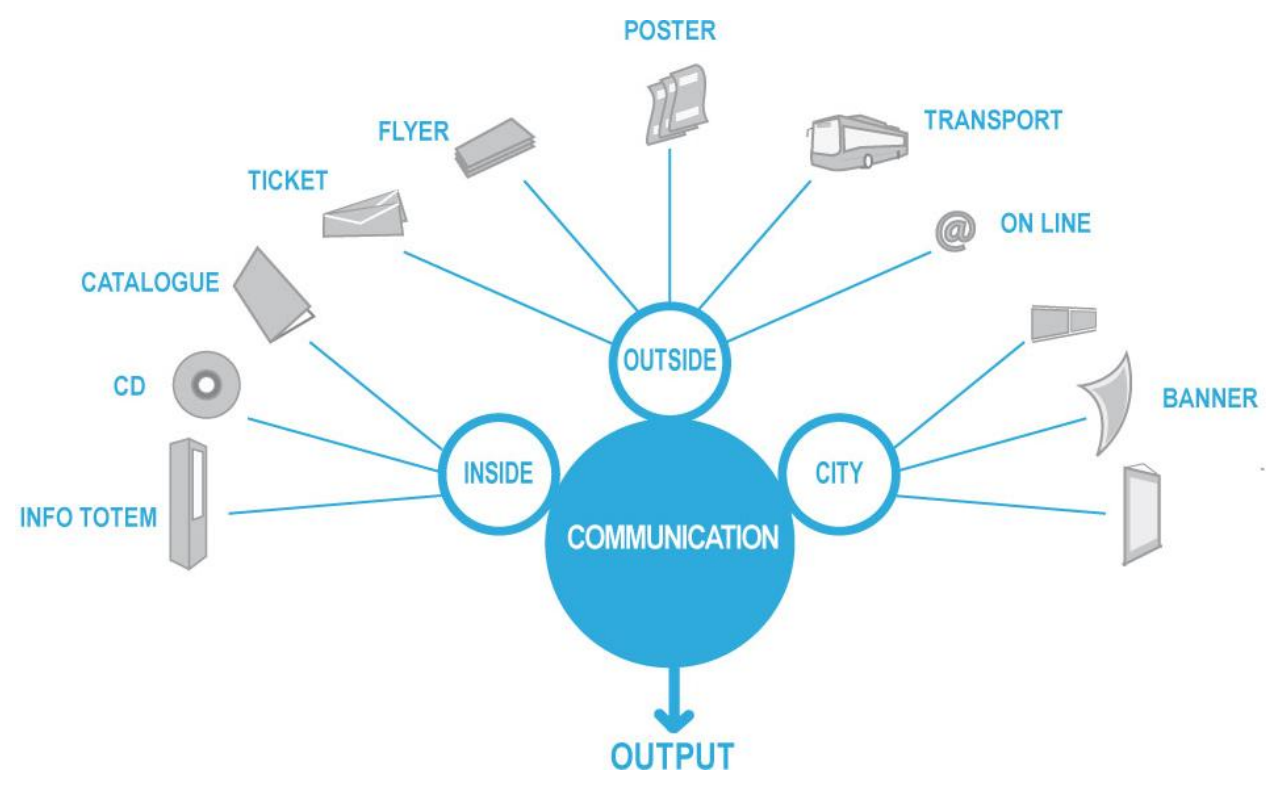

Figure 3. Event communication.

\section{Conclusion}

The System Design approach allows two main event advantages: reuse of waste and subjects cooperation. The Systemic Design methodology changes the project of an event.

Designers project not only the days of the event, but also the "pre-event phase" and the "post-event" phase.

The whole vision of the event permits to outline an holistic relief, useful to underline qualities and quantities of all involved resources.

Thanks to the analysis of the "state of the art" the designer is able to put in relation input and output flows of material and energy.

The creation of several links enables the use of waste output as resources for another process. This will make it possible to create product of "second-generation".

The second main advantage of a systemic event is the subjects' participation.

Through a "systemic view" subjects are inquired about all the details of the event: in that way they are able to recognize their environmental role.

Under the designer's leadership, all the subjects become conscious and move in a synergic way: they privilege ethical choices with priority to human health and environment.

In order to summarize the contribution of the Systemic Design methodology, it's possible to say that a "systemic event" will produce multiple benefits:

- valorisation and optimization of available resources

- waste re-use

- reduction of $\mathrm{CO} 2$ emissions

- strong connection with the land and the local culture. 


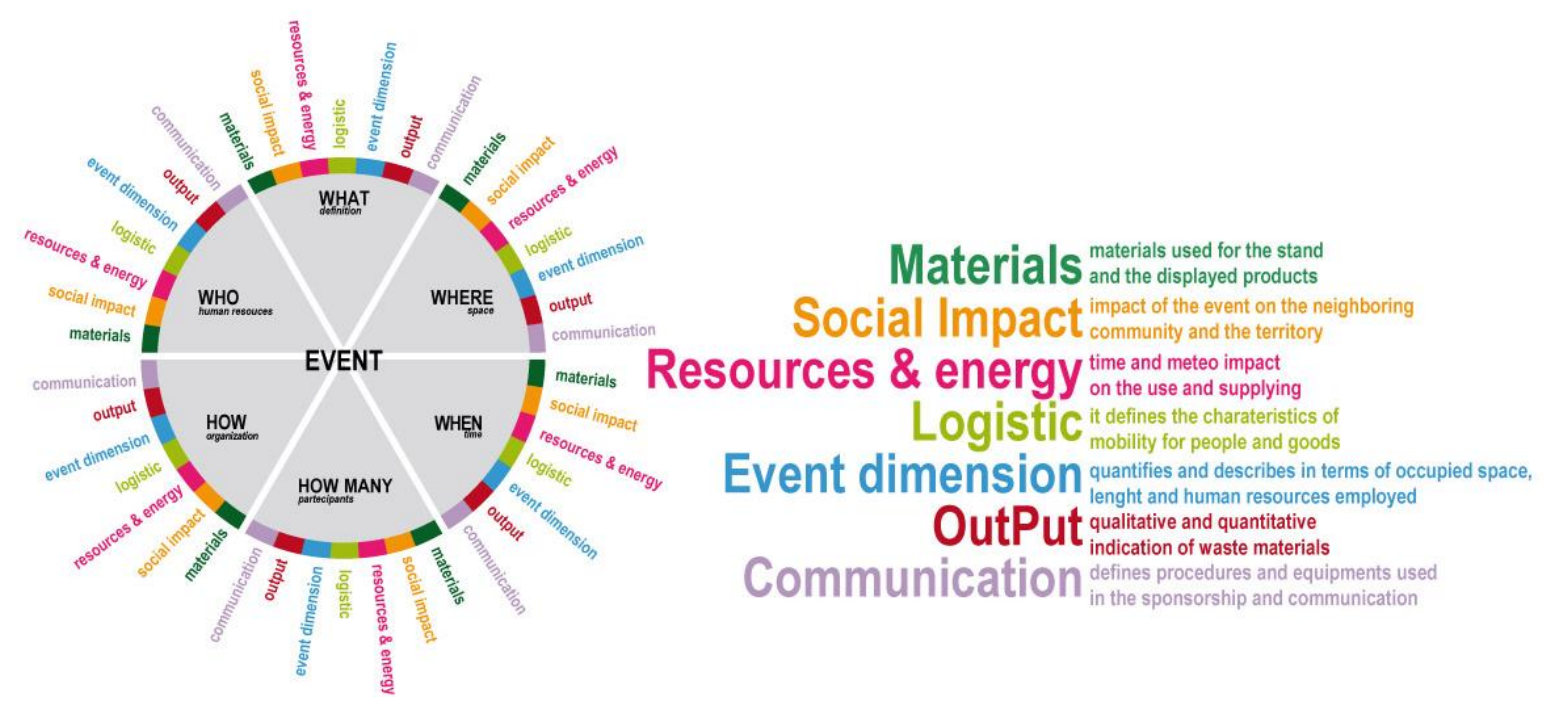

Figure 4. Energy and material flows.

\section{REFERENCES}

Castelletti, M. (2003). Marketing di relazione. Ed. UTET, Milano.

Fabris, G. (2000). Consumatore e mercato. Ed. Sperling \& Kupfer, Milan

Jones, M. (2009). Sustainable Event Management. A practical guide. Peats Ridge, Stylus.

Muzi Falconi, T. (2003). Governare le relazioni. Il Sole 24 Ore, Milano.

Pecchenino, M. (2005). Organizzare gli eventi. Come gestire convegni, manifestazioni e feste per la comunicazione d'impresa. Il Sole 24 Ore.

Raj, R., Musgrave, J. Event Management and Sustainability.

Spatrisano, A., Wilson, N. Simple steps to green meetings and events: the professional's guide to saving money and the earth.

Vender Caldarelli, E., Ferri, S., \& Ruffini, A. (2010). Ecoeventi meeting, incentivare il team building per una comunicazione sostenibile. Milano, Lupetti Editore. 